\title{
White matter changes in Wilson's disease: A radiological enigma
}

\author{
Soumava Mukherjee, Bhavesh Solanki, Goutam Guha, Shankar Prasad Saha \\ Department of Neurology, Nil Ratan Sircar Medical College and Hospital, Kolkata, West Bengal, India
}

\section{ABSTRACT}

Wilson's disease is a metabolic disorder which presents with hepatitis or hepatic decompensation commonly. Neurologic manifestations are late and include movement disorders, personality changes, and seizures. Magnetic resonance imaging (MRI) brain shows high signal changes in putamen, lentiform nucleus, thalamus, and brainstem. White matter lesions are rare. We report a child of Wilson's disease who presented to us with dystonia, rigidity, myoclonus and had symmetrical white matter changes in the fronto-parietooccipital region. Diffusion restriction in bilateral frontoparietal areas was also seen which is rare in chronic cases like ours. Atypical MRI characteristics should be considered in patients with clinical signs of neurological involvement in Wilson's disease as it is a devastating but treatable disease.

Key words: Atypical magnetic resonance imaging, white matter changes, Wilson's disease

\section{Introduction}

Metabolic disorders like Wilson's disease commonly present with hepatitis, cirrhosis, or as hepatic decompensation. Neurologic manifestations of this disease is typically a late feature, occurring in patients in early twenties. ${ }^{[1]}$ The hepatic abnormalities may be asymptomatic and thus neurologic or neuropsychiatric complaints may be the initial and early clinical presentation. We present a child who came to us with dystonia, rigidity, and myoclonic jerks and was subsequently diagnosed to have Wilson's disease. The magnetic resonance imaging (MRI) brain of this patient revealed rare manifestations of symmetrical white matter signal changes.

\section{Address for correspondence:}

Dr. Soumava Mukherjee, Room No. 61

N.H.Q Hostel, Nil Ratan Sircar Medical College and Hospital,

138 A.J.C Bose Road, Kolkata - 700014

West Bengal, India.

E-mail: dr.soumava@gmail.com

\begin{tabular}{|l|l|}
\hline \multicolumn{2}{|c|}{ Access this article online } \\
\hline Quick Response Code: & Website: \\
\hline & www.ruralneuropractice.com \\
\cline { 2 - 2 } & \\
\hline & DOI: \\
\hline & $10.4103 / 0976-3147.176195$ \\
\hline
\end{tabular}

\section{Case Report}

A 9-year-old male child presented to us with a history of exanthematous fever 8 months back followed by progressive difficulty in walking. Subsequently, he developed abnormal posturing of his limbs and tremulousness of hands. After about 3 months, his mother noticed that the child had a progressive decrease in spontaneous speech without any complaints of incoherent speech. He developed involuntary jerky movements of all four limbs lasting for seconds since past 2 months which used to persist during sleep. There was no history suggestive of cranial nerve involvement, weakness of limbs, and loss of consciousness. He had a normal birth and immunization history and no history of similar complaints in his family members.

Examination of the patient revealed normal vital signs and heart and breath sounds. There was restricted vertical saccades and hypometric horizontal saccades with impaired vestibulo ocular reflex. Rigidity was

This is an open access article distributed under the terms of the Creative Commons Attribution-NonCommercial-ShareAlike 3.0 License, which allows others to remix, tweak, and build upon the work non-commercially, as long as the author is credited and the new creations are licensed under the identical terms.

For reprints contact: reprints@medknow.com

How to cite this article: Mukherjee S, Solanki B, Guha G, Saha SP. White matter changes in Wilson's disease: A radiological enigma. J Neurosci Rural Pract 2016;7:447-9. 
present in all four limbs. Power in all groups of muscles was normal with preserved reflexes. Sensory and cerebellar examination was normal. Gait was ataxic. Myoclonic jerks involving distal upper and lower limbs were observed.

Considering the history and examination, a possibility of a postinfective demyelinating disease of the central nervous system was our working diagnosis. Routine investigations were normal. An initial MRI brain (0.5T) showed T2 hyperintense lesions in parietooccipital cortex and bilateral putamen. Cerebrospinal fluid (CSF) study was negative for infective etiology and pan neurotropic viral polymerase chain reaction panel negative. Electroencephalogram (EEG) showed paroxysmal spike and wave epileptiform discharges. Cognitive decline, myoclonus, subcortical involvement in brain imaging and normal CSF study made us to consider the possibility of a neurometabolic disorder with rapid decompensation. Screening for metabolic disease revealed a low serum ceruloplasmin $(4 \mathrm{mg} / \mathrm{dl})$. Subsequent investigations showed $24 \mathrm{~h}$ urine copper $459.33 \mathrm{ug} / \mathrm{dl}$ (normal < $60 \mathrm{ug} / \mathrm{dl}$ ) and the presence of Kayser-Fleischer ring on slit lamp examination. Ultrasonography abdomen was normal. The patient had cognitive decline with exanthematous fever and myoclonus, but in view of the absence of periodicity in epileptiform discharges in EEG and high $24 \mathrm{~h}$ urine, copper excretion possibility of Subacute sclerosing panencephalitis was excluded. Serum antithyroid peroxidase was negative. Repeat MRI brain (1.5T) showed focal areas of hyperintense signal changes in the thalamus, basal ganglia, and bilateral subcortical parieto temporal and frontal white matter [Figures 1 and 2]. There was diffusion restriction in bilateral thalamus and frontoparietal regions [Figure 3].

The patient was put on slow titrated doses of D-penicillamine (250 $\mathrm{mg}$ daily at the time of discharge) to avoid any abrupt worsening of neurologic signs along with zinc acetate $100 \mathrm{mg}$ thrice daily and pyridoxine, ensuring that the drugs were administered at least $1 \mathrm{~h}$ apart. There was no deterioration in the neurologic complaints, and he did not develop any adverse sensitivity reactions to the drugs. The patient was discharged and put on follow-up (subsequent visit not done at the time of reporting this article).

\section{Discussion}

Wilson's disease or hepatolenticular degeneration is an autosomal recessive disorder caused by a mutation in the ATP7B gene. Clinical manifestations of this disease are due to abnormal copper deposition in tissues,

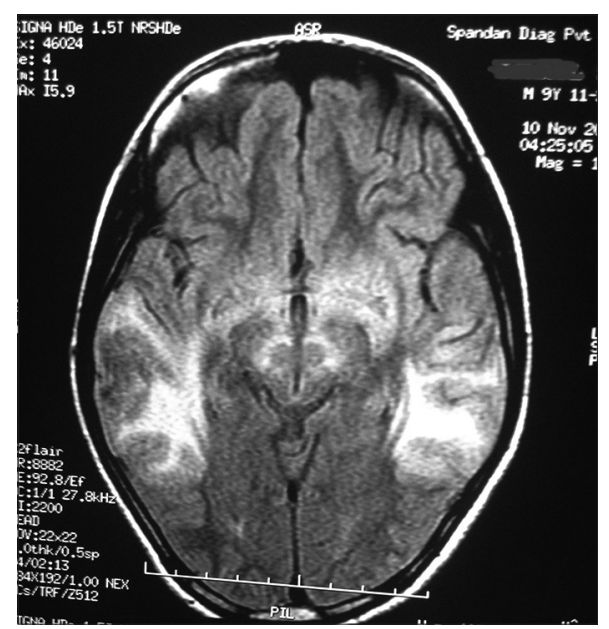

Figure 1: Magnetic resonance imaging (T2 flair weighted sequences) shows symmetrical hyperintensities in temporoparietal region

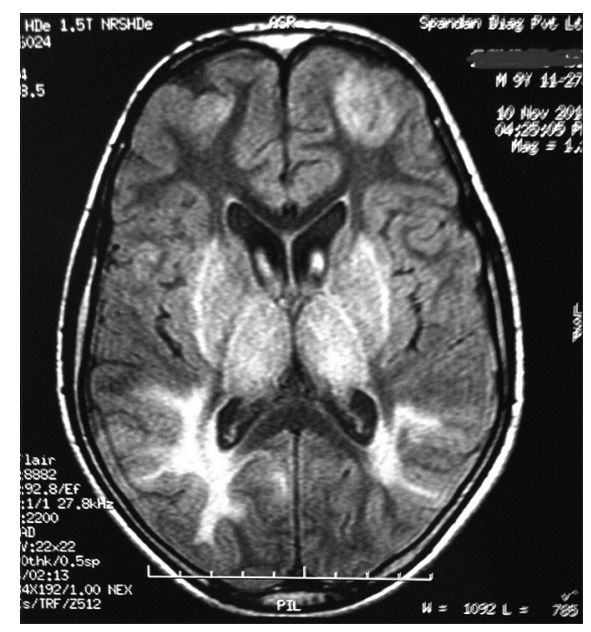

Figure 2: Magnetic resonance imaging (T2 flair weighted sequences) shows symmetrical hyperintensities in frontal and parieto-occipital region and basal ganglia

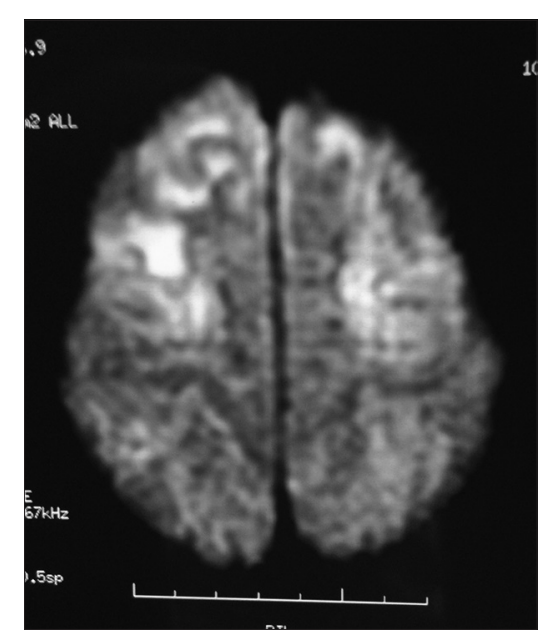

Figure 3: Magnetic resonance imaging (diffusion-weighted imaging sequences) shows diffusion restriction in bilateral fronto-parietal region

primarily the liver and brain. In most populations the frequency of this disease is about 1 in $30,000-40,000 .{ }^{[1]}$ 
The neurologic manifestations of this disorder include dystonia, incoordination, tremor, and dysarthria. ${ }^{[1]}$

MRI brain imaging in patients with Wilson's disease commonly shows hyperintensities in the lentiform and caudate nucleus, thalamus, and midbrain (sparing the red nucleus and substantia nigra). ${ }^{[2]}$ The high signal T2 images seen in these regions are attributed to edema, gliosis, or cystic degeneration. ${ }^{[3,4]}$ Sometimes hyperintensities in long transgressive-regressive sequences have also been observed and are postulated to be due to the paramagnetic effect of copper deposition ${ }^{[4]}$ Rarely, diffusion restriction in MRI imaging may be observed due to cytotoxic edema or inflammation but are usually not observed in chronic cases..$^{[5]}$

White matter abnormalities in MRI brain in patients with Wilson's disease is rarely reported. Nazer et al. studied six patients with Wilson's disease and found no white matter abnormalities. ${ }^{[6]}$ In an Indian study by Jha et al. reported an incidence of $10 \% .{ }^{[7]}$ The largest incidence of white matter abnormalities was reported by van Wassenaer-van Hall et al. in 1995 (41\%). ${ }^{[8]}$ They postulated that the white matter abnormalities mainly involved three tracts: Dentatorubral, thalamopontocerebellar, and corticospinal. In contrast to gray matter lesions which were mostly symmetrical, white matter lesions in patients with Wilsons disease are asymmetrical. ${ }^{[4]}$ White matter abnormalities along with subcortical cyst were reported by Patell et al. in a 14-year-old girl who had chronic liver disease, unlike our patient who had no evidence of hepatitis. ${ }^{[9]}$

In our patient extensive white matter lesions were observed in bilateral frontal and parietooccipital region. They were symmetrical. Both these findings have been rarely reported in imaging of patients with Wilson's disease. Diffusion restriction was observed in bilateral fronto-parietal region. This finding is normally observed in acute cases, but our patient had a history of 8 months. Differential diagnosis of such white matter changes is HIV encephalopathy, acute disseminated encephalomyelitis, and posthypoxic encephalopathy.
All conditions were excluded in our patient by relevant history and investigations. Cerebral and cerebellar atrophy with ventricular dilatation have been reported in Wilson's disease, but no such feature was present in our patient. ${ }^{[7]}$

We report this case to highlight presence of following atypical MRI brain findings in a potentially devastating but treatable disease like Wilson's disease:

- Symmetrical white matter hyperintensities involving frontal and parietooccipital region

- Diffusion restriction in bilateral fronto-parietal region in a patient with a history of 8 months which could indicate an ongoing metabolic insult to the brain.

\section{Financial support and sponsorship \\ Nil.}

\section{Conflicts of interest}

There are no conflicts of interest.

\section{References}

1. Brewer GJ. Wilsons disease. In: Harrisons Principles of Internal Medicine. $18^{\text {th }}$ ed. New york: McGraw-Hill; 2012. p. 3188-90.

2. Singh P, Ahluwalia A, Saggar K, Grewal CS. Wilson's disease: MRI features. J Pediatr Neurosci 2011;6:27-8.

3. van Wassenaer-van Hall $H N$, van den Heuvel AG, Algra A, Hoogenraad TU, Mali WP. Wilson disease: Findings at MR imaging and CT of the brain with clinical correlation. Radiology 1996;198:531-6.

4. Sener RN. Wilson's disease: MRI demonstration of cavitations in basal ganglia and thalami. Pediatr Radiol 1993;23:157.

5. Yousaf M, Kumar M, Ramakrishnaiah R, Vanhemert R, Angtuaco E. Atypical MRI features involving the brain in Wilson's disease. Radiol Case Rep 2009;4:312.

6. Nazer H, Brismar J, al-Kawi MZ, Gunasekaran TS, Jorulf KH. Magnetic resonance imaging of the brain in Wilson's disease. Neuroradiology 1993;35:130-3.

7. Jha SK, Behari M, Ahuja GK. Wilson's disease: Clinical and radiological features. J Assoc Physicians India 1998;46:602-5.

8. van Wassenaer-van Hall $H N$, van den Heuvel AG, Jansen GH, Hoogenraad TU, Mali WP. Cranial MR in Wilson disease: Abnormal white matter in extrapyramidal and pyramidal tracts. AJNR Am J Neuroradiol 1995;16:2021-7.

9. Patell R, Dosi R, Joshi HK, Storz D. Atypical neuroimaging in Wilson's disease. BMJ Case Rep 2014;2014. pii: Bcr2013200100. 